\title{
Mediação pedagógica em tempos pandêmicos: relatos de professores da educação básica
}

\author{
Alba Cristhiane Santana* \\ Renato Barros de Almeida**
}

\begin{abstract}
Resumo
Este artigo tem o objetivo de discutir sobre o processo de mediação pedagógica no período da pandemia da Covid-19, considerando a utilização das tecnologias, com base em relatos de professores sobre aulas na educação básica. A mediação pedagógica é compreendida como um processo complexo e dinâmico que envolve a ação planejada e intencional dos professores, abrangendo os aspectos didático-pedagógicos, os contextos envolvidos e as relações entre as pessoas. Foi realizado um estudo qualitativo que se caracterizou por um processo interpretativo dos significados produzidos pelos participantes. Participaram seis professores que atuam na educação básica, que responderam a questões relacionadas à prática docente nesse momento de pandemia e de atividades escolares não presenciais. Na discussão sobre os relatos das aulas foram destacados os temas recorrentes, considerando-se as concepções sobre o processo educativo e as atividades não presenciais durante a pandemia, as condições de trabalho nesse contexto, as metodologias e as tecnologias utilizadas, as formas de interação e de participação dos alunos e as dificuldades para a mediação de forma não presencial.
\end{abstract}

Palavras-chave: mediação pedagógica, tecnologias, educação básica, tempos pandêmicos, covid-19.

\section{Pedagogical mediation in pandemic times: basic education teacher reports}

\section{Abstract}

This article aims to discuss the pedagogical mediation process during the COVID-19 pandemic period, taking into consideration the use of technologies, based on teachers' reports on basic education classes. Pedagogical mediation is understood as a complex and dynamic process that involves the planned and intentional action of teachers, encompassing didactic-pedagogical aspects, contexts and social relations. A qualitative study that was characterized by an interpretative process of the meanings produced by the participants was carried out. The participants were six teachers who work in basic education. They answered questions related to teaching practice at this time of pandemic and non-presential activities. In the discussion about the reports of the classes, recurrent themes were highlighted, such as: the conceptions about the educational process and the non-presential activities during the pandemic, the working conditions in this context, the methodologies and technologies used, the forms of interaction and student participation and difficulties in mediation in a non-face-to-face class.

Keywords: pedagogical mediation, technologies, basic education, pandemic times, covid-19.

\footnotetext{
* Doutora em Psicologia do Desenvolvimento pela Universidade de Brasília - UnB. Professora Associada - Faculdade de Letras - UFG - Psicologia da Educação. E-mail: alba_mata@ufg.br.

** Doutor em Educação pela Faculdade de Educação da Universidade de Brasília - UNB. Professor efetivo da Pontifícia Universidade Católica de Goiás - PUC/GO - na Escola de Formação de Professores e Humanidades; professor efetivo da Universidade Estadual de Goiás - UEG - Campus Jaraguá. Coordenador do Grupo de Estudos e Pesquisas em Formação de Professores e Currículo - GEPFOPC. E-mail: renato.almeida@ueg.br.
} 


\section{Introdução}

Este artigo tem o objetivo de discutir sobre o processo de mediação pedagógica no período da pandemia da Covid-19, considerando a utilização das tecnologias e com base em relatos de professores sobre aulas na educação básica. Compreende-se a mediação pedagógica como um processo complexo e dinâmico que envolve a ação planejada e intencional dos professores para promover a relação entre o aluno e os objetos de conhecimento, contribuindo com o seu desenvolvimento, um processo que abrange os distintos elementos que compõem os aspectos didático-pedagógicos, bem como os diferentes contextos envolvidos e as relações estabelecidas entre os sujeitos. Adotamos uma concepção de mediação pedagógica fundamentada nos estudos de Vigotski (1934/2010, 2003) e nos conceitos apresentados por Libâneo (2008, 2011) e Leite (2012), que serão discutidos posteriormente.

A proposta de estudar a mediação pedagógica no período da pandemia se deve ao interesse de se compreender a situação de suspensão das atividades presenciais vivenciada na educação básica. Tal situação foi determinada em decorrência da declaração da Organização Mundial da Saúde (OMS), em março de 2020, de pandemia da Covid-19, por causa da disseminação comunitária do vírus em todos os continentes. Uma situação de pandemia obriga os países a acionarem medidas preventivas para salvar vidas e minimizar o impacto da doença. No Brasil, o Ministério da Saúde decretou emergência em saúde pública de importância nacional e, na sequência, legislações nos níveis federal, estadual e municipal foram publicadas com determinações para o enfrentamento da pandemia, como o distanciamento social e a suspensão das atividades escolares, dentre outras.

Segundo a Unesco, a suspensão das atividades escolares provocou um impacto em mais de $70 \%$ da população estudantil do mundo, uma vez que vários países programaram o fechamento das escolas, afetando bilhões de estudantes (UNESCO, 2020). No Brasil, de acordo com o Instituto Nacional de Estudos e Pesquisas Educacionais Anísio Teixeira (Inep), os estudantes da educação básica, que abrangem cerca de 49 milhões de pessoas (INEP, 2020), tiveram suas atividades escolares suspensas devido à pandemia.

O Ministério da Educação (MEC) e o Conselho Nacional de Educação (CNE) orientaram, a exemplo da Portaria MEC n ${ }^{\circ} 343$, de 17/03/2020 e do Parecer CNE/CP $n^{\circ}$ 
5, de 28/04/2020, a substituição das aulas presenciais por atividades não presenciais durante a pandemia, com a utilização de meios digitais. Nessa direção, conselhos estaduais e municipais de educação emitiram pareceres com orientações para as instituições de ensino de seus respectivos sistemas sobre o desenvolvimento de atividades não presenciais, bem como a reorganização do calendário escolar e da carga horária.

Em decorrência deste cenário, as instituições de educação básica no país, com base em legislações, instruções normativas e orientações publicadas, foram se organizando e iniciaram a realização de atividades não presenciais, mediadas ou não por tecnologias digitais de informação e comunicação. Vale destacar que o Parecer CNE/CP n 5/2020 orienta que as atividades não presenciais podem ocorrer por meios digitais, como videoaulas, plataformas digitais, redes sociais; por programas de televisão ou rádio; por material didático impresso a ser distribuído aos alunos e famílias; e por projetos, pesquisas e atividades indicadas nos materiais didáticos (BRASIL, 2020).

Em relação à situação das aulas na educação básica, no mês de novembro de 2020, dados da Federação Nacional de Escolas Particulares (Fenep) e do Conselho Nacional de Secretários de Educação dos Estados e Distrito Federal (Consed) informam que a maioria dos 26 estados brasileiros e o Distrito Federal estão sem previsão de retorno total às aulas presenciais na Educação Básica, embora muitos já possuam autorização legal para um retorno escalonado ainda neste ano (FENEP, 2020; CONSED, 2020). Esse é um cenário que demonstra que o sistema de ensino no país deverá conviver, ainda por um tempo, com atividades não presenciais.

A pandemia surpreendeu a todos e, nos espaços educativos, professores e alunos tiveram que passar por mudanças significativas de forma muito rápida, alterando práticas tradicionais no processo de ensino-aprendizagem, como as metodologias, a realização dos exercícios escolares e as formas de interação. A utilização das Tecnologias Digitais de Informação e Comunicação (TDIC) se tornou o meio mais comum nesse momento, exigindo dos profissionais uma preparação quase instantânea para desenvolver uma prática mediada pelas tecnologias.

As modificações nas formas de mediação pedagógica que estão ocorrendo nas aulas da educação básica podem ter desdobramentos no processo de ensino-aprendizagem após a pandemia e essa é uma situação que provoca o interesse em refletir sobre as possibilidades que são geradas para a prática docente com as contribuições da tecnologia. 
Assim, neste artigo apresentamos, inicialmente, a nossa compreensão sobre a mediação pedagógica e sobre as tecnologias na educação. Na sequência, apresentamos os relatos de professores, evidenciando os aspectos metodológicos envolvidos no estudo, bem como as discussões sobre a mediação pedagógica durante a pandemia.

\section{Mediação pedagógica: considerações conceituais}

A mediação pedagógica se refere à ação do professor nos contextos educativos e pode assumir distintas definições, a depender da concepção teórica adotada e dos

objetivos da discussão. É possível observar definições a partir de perspectivas mais técnicas, com ênfase nas metodologias e nos recursos didáticos, mas também é possível identificar perspectivas mais amplas, que focalizam os variados fatores que compõem o processo educativo, envolvendo a prática do professor, suas concepções e os variados contextos em que está inserido.

Adotamos uma concepção que percebe a mediação como a ação intencional do professor de modo a contribuir com o desenvolvimento das capacidades intelectuais dos alunos, por meio dos conteúdos. Em outras palavras, o ensino é o meio pelo qual os sujeitos aprendem e desenvolvem as capacidades humanas formadas ao longo da história e objetivadas na cultura material e espiritual (LIBÂNEO, 2008).

A compreensão de mediação parte dos estudos de Vigotski (1934/2010, 2003), com ênfase no conceito de mediação semiótica, que se refere ao processo dialógico de interação das pessoas com o mundo, no qual são produzidos e negociados significados sobre si mesmo, os outros e a realidade. Na interação humana é construída uma rede de significados que fundamenta e orienta a relação entre as pessoas, com sentidos pessoais, abrangendo a singularidade histórica e social do sujeito e significados coletivos, com produções históricas e sociais sobre os diferentes aspectos dos contextos humanos.

Os significados constituem as formas culturais de comportamento e são produzidos por meio da linguagem, que é o sistema semiótico básico, composto por signos que são internalizados e são responsáveis pelo desenvolvimento da atividade psicológica. Segundo Vigotski (2003, p. 65) “a internalização das atividades socialmente enraizadas e historicamente desenvolvidas constitui o aspecto característico da psicologia humana". 
O contexto educativo é constituído por um sistema semiótico complexo com produção contínua de significados relacionados às pessoas, aos objetos de conhecimento e aos diferentes fenômenos do mundo. Na interação entre professor e aluno observa-se um movimento acentuado de apropriação e produção de significados que mobiliza a promoção de aprendizagem e de desenvolvimento.

A mediação pedagógica implica em uma ação planejada do professor, um processo que contribui para a relação do aluno com o objeto de conhecimento por meio de diferentes elementos didático-pedagógicos que constituem o processo de ensinar e de aprender. Tais elementos abrangem a definição dos objetivos do ensino, a seleção do conteúdo curricular e dos materiais e recursos didáticos, o planejamento da metodologia de ensino e de avaliação e a relação estabelecida entre professores e alunos.

Concordamos com a discussão de Libâneo (2011) de que a prática do professor é um processo de mediação entre o aluno e os objetos de conhecimento com vistas à apropriação da cultura e da ciência, além da promoção do seu desenvolvimento. É uma definição que parte de uma concepção em que ensino, aprendizagem e desenvolvimento humano são compreendidos como processos que ocorrem de forma indissociável.

É importante assinalar que no planejamento de sua ação o professor se fundamenta em várias concepções, que incluem os objetivos da educação e da escola, o seu papel no processo educativo, o papel do aluno e de sua família, bem como valores e crenças sobre o ser humano, seu comportamento, sua capacidade de aprender e de se desenvolver. E ainda é uma prática que ocorre em contextos sociais e políticos concretos, que possibilitam as condições para o ensino-aprendizagem. Por isso, a mediação do professor é vista como um processo complexo e multideterminado.

As condições da mediação pedagógica dependem, também, da ação intencional do professor e, segundo Leite (2012), isso implica nas decisões pedagógicas acerca dos aspectos que compõem o processo educativo e que podem favorecer (ou não) o desenvolvimento do aluno. Uma decisão pedagógica importante se refere ao ponto de partida do ensino e, de acordo com o autor, o planejamento da mediação do professor deve partir dos conhecimentos e das características do aluno, reconhecendo os prérequisitos necessários para o ensino e a aprendizagem.

Reconhecer o aluno como um sujeito singular, com seus conhecimentos, habilidades e concepções, favorece as condições para a mediação com os objetos de 
conhecimento. Leite (2012) discute que a mediação do professor contribui para a apropriação e a construção de conhecimentos, para o desenvolvimento cognitivo e, também, mobiliza afetos, motivações, interesses e formas de interação que possibilitam o desenvolvimento das pessoas envolvidas. Vale assinalar que, de acordo com Vigotski (1934/2010), pensamento e afeto são processos psicológicos superiores indissociáveis.

O processo de mediação pedagógica é compreendido, portanto, como complexo e dinâmico, pois envolve não só a definição dos elementos didático-pedagógicos que compõem a ação de ensinar, mas também abrange a articulação contínua entre as características do professor, do aluno, dos contextos e das relações estabelecidas entre os sujeitos, os objetos do conhecimento e destes com as situações de ensino e aprendizagem. Ao se pensar na utilização das tecnologias no processo ensino-aprendizagem, é necessário considerar essa complexidade que caracteriza a mediação do professor.

\section{Tecnologias e ensino não presencial: considerações gerais}

As tecnologias são compreendidas nesta discussão como elementos que constituem a mediação pedagógica, com base nos conceitos vigotskianos de instrumentos e signos. Para esse autor, na relação do sujeito com a natureza, o instrumento é orientado externamente e o signo é orientado internamente, dirigido para o controle do próprio indivíduo, de maneira intrínseca, ou seja: "o controle da natureza e o controle do comportamento estão mutuamente ligados, assim como a alteração provocada pelo homem sobre a natureza altera a própria natureza do homem" (VIGOTSKI, 2003, p. 73).

O desenvolvimento humano é mediado por instrumentos e signos que são construídos histórica e culturalmente, transformando os sujeitos e seus contextos. Lalueza, Crespo e Camps (2010) discutem que cada cultura e momento histórico se caracterizam por desenvolverem sistemas de ferramentas - instrumentos e signos, que orientam a atividade humana, com possibilidades para o desenvolvimento dos sujeitos e da sociedade, uma vez que geram práticas cotidianas que vão mediar as relações sociais e culturais. Esses autores assinalam que as TDIC impactam o desenvolvimento humano, à medida que potencializam habilidades e capacidades com a utilização de novas ferramentas, propiciando formas singulares de pensar, de agir e de sentir. 
Segundo Coll e Monereo (2010, p. 17), as TDIC se referem a um sistema de signos - "linguagem oral, linguagem escrita, imagens estáticas, imagens em movimento, símbolos matemáticos, notações musicais etc" ()- representativos de informações que podem ser produzidas e compartilhadas. Os autores assinalam que as tecnologias passaram por distintas fases de desenvolvimento ao longo da história, como instrumentos e signos, de acordo com as características e demandas de cada tempo e espaço. As TDIC abrangem a linguagem digital desenvolvida em mídias geradas por diferentes equipamentos digitais e pela internet, que possibilitam o "compartilhamento de qualquer quantidade de informação de maneira praticamente instantânea, a partir de qualquer lugar e na forma preferida, e com um custo muito baixo" (COLL; MONEREO, 2010, p. 20). Nessa perspectiva, entende-se que as TDIC possibilitam formas de pensar, aprender e conhecer, bem como orientam o desenvolvimento cognitivo, social e emocional dos sujeitos.

$\mathrm{Na}$ atualidade, observa-se a presença intensa de tecnologias digitais nos diferentes contextos, nos espaços sociais, culturais, profissionais, escolares, promovendo transformações nos processos de informação e de comunicação. É um cenário que gera mudanças na forma de interação humana, motivando o desenvolvimento de capacidades e habilidades variadas, de modo a atender às exigências de uma sociedade em constante transformação. Estudiosos na área defendem que esse processo de desenvolvimento implica em atuar de forma crítica, considerando os contextos socioculturais, econômicos e políticos envolvidos nos significados, objetivos e valores atribuídos às TDIC (ARAÚJO; ECHALAR; PEIXOTO, 2018; MOREIRA; SCHLEMMER, 2020).

Moreira e Schlemmer (2020) apontam que os contextos sociais e pedagógicos contemporâneos têm se transformado com a utilização de tecnologias digitais e de redes de comunicação digitais, com apoio da internet, proporcionando oportunidade de inovação, integração, inclusão, flexibilização e personalização da aprendizagem, com base em uma mudança de paradigma. Os autores alertam que as tecnologias digitais e a internet não geram alterações instantâneas nos currículos e nas práticas pedagógicas, uma vez que o elemento mobilizador não é a tecnologia, mas as concepções e as condições de apropriação tecnológica.

No período da pandemia da Covid-19, com a necessidade de atividades não presenciais na educação, as tecnologias passaram a ser utilizadas de forma intensa nos 
diferentes espaços educativos. Como assinala Moreira e Schlemmer (2020), ocorreu uma migração forçada para a realidade online, com utilização acentuada das tecnologias, com transferência e adaptação de metodologias típicas do ensino presencial, a partir de uma proposta denominada de ensino remoto emergencial. Os autores analisam que nesse cenário, o uso das tecnologias ainda se fundamenta em uma perspectiva meramente instrumental, com pouca compreensão sobre as possibilidades de desenvolvimento que a linguagem das tecnologias gera, conforme discutido anteriormente.

Araújo, Echalar e Peixoto (2018) problematizam que o processo educativo realizado com atividades não presenciais, por meio das tecnologias, envolve os mesmos elementos do trabalho didático-pedagógico do ensino presencial, uma vez que é composto pelos objetivos de ensino, os conteúdos e as metodologias. Segundo os autores, a definição de um curso online se dá em função das concepções pedagógicas que são adotadas e não dos instrumentos tecnológicos que são utilizados.

Vale considerar também que o ensino não presencial promove novas formas de interação, entre professores e alunos e entre alunos e objetos do conhecimento, que interferem no desenvolvimento do processo educativo. Segundo Kenski (2020), o protagonismo dos alunos é modificado no ensino mediado por tecnologias digitais, com novas possibilidades de interação e com trajetórias definidas de acordo com as condições e necessidades de cada um. A autora destaca três tipos de interações no ensino online, abrangendo: os aspectos técnicos, relacionados aos ambientes e recursos tecnológicos; os aspectos didáticos, da mediação do professor; e os aspectos humanos, vivenciados entre os sujeitos envolvidos.

Uma pesquisa da Fundação Carlos Chagas (FCC, 2020), realizada com mais de quatorze mil professores da rede pública e privada do país, demonstra como os professores percebem o ensino no momento da pandemia. Os dados indicam que a suspensão das aulas presenciais gerou um aumento expressivo de utilização de tecnologias na educação básica, incluindo a formação dos profissionais em cursos a distância, comunicação e interação dos professores com seus colegas, alunos e familiares, além de novas estratégias de ensino.

As tecnologias digitais passaram a fazer parte da mediação dos professores de formas diversas, abrangendo a utilização de plataformas digitais, aplicativos e redes sociais para aulas online, gravação de videoaulas, distribuição de materiais didáticos, 
realização de atividades e interação com alunos e família. As informações da pesquisa evidenciam, também, que a maioria dos professores mantém o conteúdo da disciplina conforme estava previsto no ensino presencial e que poucos indicaram que organizam o tempo da aula entre conteúdo curricular, orientações sobre a pandemia e outros temas trazidos pelos alunos (FCC, 2020). Dessa maneira, observa-se uma adaptação do ensino presencial às condições do ensino não presencial.

Sobre a realização de tarefas por parte dos alunos, a pesquisa indica que os professores das escolas particulares consideraram que a maioria de seus alunos realiza as atividades. Na rede pública estadual e municipal, no entanto, os professores percebem uma participação menor dos alunos. De modo geral, os professores observam que no período da pandemia há uma diminuição da aprendizagem e do envolvimento dos alunos com as atividades escolares, em comparação com o ensino presencial (FCC, 2020).

Acredita-se que esse momento da pandemia, com a suspensão das atividades escolares presenciais, é uma oportunidade para o desenvolvimento das tecnologias na educação (BRASIL, 2020), no entanto, vale refletir: a mediação nas atividades não presenciais ocorre com base em quais concepções? E em quais condições?

Na próxima seção, fundamentados nas considerações teóricas expostas, vamos apresentar relatos de professores de educação básica sobre aulas realizadas durante a pandemia de forma não presencial. O objetivo é refletir sobre como está sendo desenvolvida a mediação pedagógica nesse período, considerando a utilização das tecnologias.

\section{Aulas na Educação Básica durante a pandemia: relatos de professores}

O estudo dos relatos sobre as aulas na educação básica ocorreu com base em pesquisas realizadas pelo Grupo de Estudos e Pesquisa sobre Mediação Pedagógica e Afetividade, desenvolvido na Universidade Federal de Goiás, coordenado e com a participação dos autores do texto. Foi realizado um estudo qualitativo que se caracteriza por um processo interpretativo dos significados produzidos pelos participantes (AGUIAR, 2006).

Participaram do estudo seis professores que trabalham com a educação básica, no ensino fundamental e médio, sendo três mulheres e três homens, das áreas de língua 
portuguesa, língua estrangeira e pedagogia. Os participantes consentiram de forma livre e esclarecida o estudo dos seus relatos. A coleta dos relatos ocorreu no mês de setembro por meio de duas questões que investigaram como estão sendo ministradas as aulas nesse momento da pandemia, com destaque para as dificuldades encontradas e para a interação com os alunos.

$\mathrm{Na}$ discussão sobre os relatos das aulas foram destacados os temas recorrentes, considerando-se a ênfase dada pelos participantes, abrangendo: as concepções sobre o processo educativo e as atividades não presenciais durante a pandemia, as condições de trabalho nesse contexto, as metodologias e as tecnologias utilizadas, as formas de interação e de participação dos alunos e as dificuldades para a mediação de forma não presencial. Optou-se por apresentar uma discussão geral dos temas recorrentes de forma dialogada com os relatos e para preservar a identidade dos participantes seus nomes foram substituídos por números (Participante 1, Participante 2, Participante 3 e assim por diante).

Os relatos dos professores demonstram que as metodologias desenvolvidas nesses tempos pandêmicos e as formas de interação que estão ocorrendo entre professores e alunos envolvem a utilização predominante de tecnologias digitais. Observamos, de modo geral, um interesse em contribuir com a aprendizagem dos alunos e uma preocupação em envolver todos no processo ensino-aprendizagem, considerando as dificuldades geradas pela pandemia e pelo distanciamento social.

Nota-se que uma percepção comum entre os participantes é de que a melhor alternativa para a educação básica nesse período pandêmico é desenvolver atividades não presenciais, apesar de não demonstrarem satisfação com a experiência: "Não me sinto satisfeito não. Mas mediante a situação, eu acho que a gente tem feito aquilo que a gente consegue" (Participante 4); e "Não estou extremamente satisfeita, mas conformada que é o que temos para o momento" (Participante 5).

A concepção sobre o processo ensino-aprendizagem que se destaca nos relatos enfatiza a importância da participação ativa dos alunos, para isso os participantes entendem que é necessário desenvolver aulas que contribuam com essa proposta. Os professores evidenciam a necessidade de metodologias que despertem o interesse dos alunos e favoreçam seu envolvimento e participação nas atividades: 
Participante 1 - É fundamental as aulas que promovam mais interação $e$ participação dos alunos.

Participante 3 - Minha maior dificuldade é conseguir chamar atenção de todos, trazer todos, mas isso em sala de aula também era um problema, mas aqui [ensino não presencial] mais ainda.

Participante 4 - Eu tenho tentando tornar as aulas ainda mais dinâmicas, pedindo que eles pesquisem as coisas.

Participante 6 - Para tentar prender a atenção dos alunos, eu tento usar alguns artifícios visuais nos slides, trazer alguma música para análise, etc.

A mediação pedagógica implica uma relação de troca entre professores e alunos, com produção contínua e dinâmica de significados a respeito do conhecimento e das situações vivenciadas, com base nas ações de cada um no processo de ensino e aprendizagem. Nessa direção, é fundamental atentar-se para as possibilidades e os formatos de participação de professores e alunos em atividades não presenciais.

Em relação às metodologias utilizadas, todos os participantes relataram que estão desenvolvendo aulas online, por meio de atividades síncronas (ou seja, professores e alunos se encontram de forma simultânea, ao vivo, em plataformas digitais) e por meio de atividades assíncronas (quando os professores disponibilizam material didático e exercícios em ambientes virtuais, e-mail ou whatsapp). De acordo com relatos dos participantes, identifica-se que as escolas estão seguindo as orientações do CNE (BRASIL, 2020) de realizar as atividades não presenciais por meios digitais:

Participante 3 - Estou fazendo minhas aulas pelo Google Meet, preparo todo o conteúdo via slides, daí eu projeto na aula.

Participante 4 - A realização das minhas aulas eu tenho feito por plataforma online, as aulas são síncronas [...] eu faço uso de PowerPoint durante as aulas, compartilho a resolução de exercícios.

Participante 5 - Estou trabalhando com aulas síncronas (a maioria delas), em plataformas digitais e com aulas assíncronas [...] atividades enviadas pelo Whatsapp.

Participante 6 - As aulas estão sendo realizadas via Zoom de maneira síncrona, sendo complementadas com atividades assíncronas numa plataforma educacional, seguindo o conteúdo programado e o calendário escolar.

Observa-se a utilização recorrente das atividades síncronas com aulas que se aproximam do formato do ensino presencial, com exposição de conteúdos. A tecnologia é utilizada como recurso que permite esse encontro, valendo destacar que as possibilidades de videochamadas já existiam antes da pandemia, mas não eram utilizadas na educação básica, e que elas apresentam características técnicas e de interação que estão sendo aprendidas por professores e alunos nesse momento de distanciamento social. 
Os relatos demonstram que as concepções do ensino presencial são a referência para a mediação a distância, a partir de adaptações nas metodologias e de inclusão de tecnologias digitais. O Participante 6 demonstra preocupação com o conteúdo: “[... ] seguindo o conteúdo programado e o calendário escolar", a Participante 3 assinala a necessidade de seguir o livro didático, como ocorria no ensino presencial “[...]não está tão diferente do que eu já fazia na sala de aula, pois eu tenho que trabalhar com o livro didático"; e o participante 4 demonstra preocupação com a adaptação dos alunos: " $O$ planejamento tem alinhado aquilo que já era feito no presencial, adaptado ao sistema remoto, porque há uma cultura de aprendizagem que os alunos já estavam acostumados".

Considerando-se as alterações geradas no contexto da pandemia e do ensino não presencial, percebe-se que a proposta é minimizar os impactos no processo de aprendizagem dos alunos. Dessa forma, os participantes citam diferentes tecnologias que utilizam para atender aos objetivos de expor os conteúdos, motivar e envolver os alunos nas atividades, abrangendo aplicativos para videochamadas, como Google Meet e Zoom; redes sociais, como WhatsApp e Instagram; vídeos do YouTube; aplicativos e softwares educativos, como Kahoot, Quizlet, Socrative e Bitmoji; slides em PowerPoint; e navegador de pesquisa, como o Google.

É interessante pensar como as tecnologias são apropriadas pelos professores. Os relatos demonstram que os participantes investem em ferramentas que possam contribuir com a exposição do conteúdo e com a participação ativa dos alunos. A Participante 3 mostra esse investimento: “[...] eu consigo trazer muito vídeo, muita imagem, muita coisa bacana, que dá pra fazer muitas brincadeiras para ensinar"; e o Participante 4, também: "Eu tenho tentando tornar as aulas ainda mais dinâmicas, pedindo que eles pesquisem e produzam as coisas no Google, no YouTube, no Bitmoji”.

No entanto, a situação da pandemia exigiu dos profissionais uma rápida adaptação e preparo para o ensino não presencial e para o uso de tecnologias, com pouco tempo para uma aprendizagem adequada sobre o tema. O Participante 1 demonstra sua dificuldade: "[...] eu encontro muitas dificuldades em como repassar conhecimento aos alunos, ou seja, quais plataformas e aplicativos utilizar"; e o Participante 6, também: "Acho que a maior dificuldade é tentar adaptar toda e qualquer atividade e metodologia para o modelo remoto". 
Como diz Moreira e Schlemmer (2020), a utilização de tecnologias não provoca alterações imediatas na prática pedagógica, pois depende das concepções e da forma de apropriação tecnológica. O Participante 4 destaca que sua maior dificuldade é a mudança de paradigma: "A maior dificuldade no começo foi aceitar isso. Aceitar que a gente não estaria mais no regime presencial, eu não tenho dificuldade com tecnologia, a dificuldade não foi a tecnologia, mas aceitar que eu teria que usar essas tecnologias".

É possível refletir que a experiência com o ensino remoto movimentou a discussão sobre a educação a distância (EAD), evidenciou concepções sobre as possibilidades de ensinar e de aprender nesse formato, considerando o perfil de professor e de aluno, bem como as significações a respeito das tecnologias na educação. Segundo Belloni (2015), espera-se na EAD um aluno autônomo e disciplinado em relação à gestão do tempo, ao planejamento e à autodireção da aprendizagem, um perfil que não atende ao que se espera na educação básica.

O ensino remoto realçou, também, as desigualdades socioculturais e econômicas no país, considerando-se as dificuldades de acesso às tecnologias digitais observadas nas pesquisas (FCC, 2020) e, ainda, nos relatos, a exemplo do que disse o Participante 6: “[...] com poucos recursos na casa dos alunos, não é possível realizar uma atividade com $100 \%$ deles". A resistência de alguns professores, relatada pelo Participante 4 demonstra a presença de desigualdades culturais em relação ao uso de tecnologias: “[...] tive vários colegas que a tecnologia foi e ainda é um grande susto, colegas que choram quando é proposta uma nova plataforma".

Além das concepções e das condições de professores e alunos na realização das atividades não presenciais, as condições institucionais, também, devem ser consideradas no desenvolvimento da mediação pedagógica. Com a suspensão das aulas presenciais, as escolas reorganizaram sua forma de trabalho, juntaram turmas e reduziram as aulas dos professores. A Participante 2 relata: "Houve a redução de aulas. Ao vivo (aulas síncronas) leciono para 9 turmas diferentes juntas"; e o Participante 6 apresenta a mesma questão: "as turmas de mesma idade assistem aula juntas, ou seja, uma aula para cerca de 120 alunos ao mesmo tempo".

As condições de trabalho proporcionadas pelas escolas provoca um questionamento sobre os objetivos e os compromissos institucionais com o processo de ensino-aprendizagem. No momento da pandemia da Covid-19 foi estabelecido um 
modelo de ensino emergencial e temporário, os objetivos do ensino presencial foram transpostos para os meios digitais (MOREIRA; SCHLEMMER, 2020). E as condições de trabalho dos professores foram alteradas de forma acentuada engendrando um cenário desfavorável para a mediação pedagógica e o processo educativo.

A forma de participação dos alunos nas aulas, também, sofreu alterações. Apesar das tecnologias permitirem formas criativas de produção, a maior dificuldade apontada pelos participantes se refere à ausência de participação dos alunos, conforme os seguintes relatos:

Participante 1 - Os alunos se cansam mais rapidamente, não se concentram tanto.

Participante 2 - A dificuldade é lidar com o fato de que muitos alunos não estão na aula, é perder o contato com muitos. Tento saber onde estão e o que fazem, me sinto incapaz diante desta situação.

Participante 3 - eu tenho um número restrito de alunos ali na minha frente, no display do Google Meet, então eu não sei se todo mundo está conseguindo aprender, eu não consigo ver o caderno de todo mundo [...] não consigo saber se eles estão corrigindo.

Participante 5 - A maior dificuldade ainda é alcançar a maioria dos alunos. Tenho, por semana, um grupo de alunos que está sempre presente e participativo, porém ainda tenho alunos que não visualizam as atividades enviadas pelo Whatsapp, não entram na aula online e não dão nenhum tipo de devolutiva.

Participante 6 - Por falta de interesse ou por ter tantas coisas mais interessantes em casa do que a aula online, os alunos participam muito pouco e é um desafio muito grande resgatá-los para as aulas.

Considerando as discussões de Kenski (2020) sobre os três tipos de interações propiciadas no ensino online (técnica, didática e humana), os relatos dos participantes vislumbram dificuldades relacionadas ao aspecto didático e, talvez, ao aspecto técnico, relacionado a questões de acesso. $\mathrm{O}$ fato de os alunos não estarem presentes nas aulas síncronas ou não visualizarem as atividades assíncronas pode indicar dificuldades técnicas de acesso à internet ou de manuseio das tecnologias digitais. E a falta de interesse ou de concentração dos alunos nas aulas online pode sinalizar dificuldade ou resistência com aulas expositivas, enfim, seria interessante ouvir os alunos sobre essa questão, pois, como diz Leite (2012), é fundamental desenvolver a mediação considerando as características e as condições dos alunos. 
Por outro lado, percebe-se que as tecnologias possibilitam, também, uma interação humana (KENSKI, 2020), que não seria possível nesse momento de distanciamento social por causa da pandemia:

\begin{abstract}
Participante $4-[\ldots]$ os pets vêm participar às vezes das aulas, os animaizinhos, né? isso é um momento afetivamente positivo. De você se desarmar enquanto professor, os alunos se desarmarem enquanto alunos e há uma interação afetivamente muito boa nesse momento.

Participante 5 - Com as aulas síncronas consigo ter uma proximidade maior com os alunos. Conversamos sobre o dia, o que eles andam fazendo, percebo os cortes de cabelo, o irmão que aparece no vídeo, a avó que passa e eu pergunto se ele está com visita. Tudo isso misturado ao conteúdo que está sendo ministrado. Meus filhos aparecem no meio da aula para darem bom dia. Os alunos adoram ter esta intimidade, sentem que estão na minha casa (e estão). O bate papo com os colegas também é intenso, o chat "bomba" durante a aula com fofocas e dicas de jogos.
\end{abstract}

As formas de interação desenvolvidas no ensino remoto, de acordo com o relato dos participantes, apresentam características que demandam maiores estudos para que seja possível identificar as especificidades das questões envolvidas. Segundo Kenski (2020), a interação online depende em grande parte da capacidade de comunicabilidade entre os sujeitos, o ambiente virtual, as atividades e os conteúdos. E, considerando-se a frequência de atividades síncronas do ensino remoto emergencial, é oportuno dizer que depende, também, da capacidade de comunicação síncrona entre professores e alunos.

A mediação do professor mobiliza afetos, motivações e interesses (LEITE, 2012), portanto, é importante considerar as formas de interação e de trocas afetivas no processo de ensino-aprendizagem. As Participantes 2 e 3 relatam que a distância física dos alunos e as dificuldades de comunicação geradas pelas dificuldades técnicas com as tecnologias as tem afetado emocionalmente: "Estou ciente que posso desmotivar meus alunos, assim como me desmotivo às vezes" (Participante 2); a Participante 5 percebe que as aulas síncronas possibilitam uma boa troca afetiva: "Sinto-me mais perto deles, damos risadas, batemos papo, cantamos"; o Participante 6 percebe que as trocas afetivas estão prejudicadas nesse formato a distância: "As trocas afetivas tendem a acontecer somente com os alunos que mais participam das aulas, isto é, com a minoria".

Os aspectos discutidos com base nos relatos, considerando-se as limitações deste artigo, evidenciam que as tecnologias digitais e os contextos virtuais de aprendizagem 
oferecem possibilidades para a mediação pedagógica e o processo educativo. No entanto, apresentam, também, desafios que demandam estudos e planejamento para que ocorram efetivamente contribuições para o desenvolvimento social, cognitivo e afetivo de professores e alunos.

\section{Considerações finais}

Discutimos neste artigo, conforme o objetivo proposto, o processo de mediação pedagógica no período da pandemia da Covid-19, considerando-se a utilização das tecnologias, com base em relatos de professores sobre aulas na educação básica. Identificamos que nesse contexto ocorre uma utilização expressiva de tecnologias digitais, com o propósito de fazer uma transposição do ensino presencial para um formato remoto, devido ao distanciamento social.

Entendemos que o papel da escola é contribuir para que os alunos desenvolvam suas capacidades intelectuais, ao mesmo tempo em que se apropriam dos conteúdos escolares, de modo que as metodologias de ensino se constituam para além de um conjunto de procedimentos e técnicas de ensino. Espera-se que as metodologias consistam em instrumentos de mediação para apoiar os alunos na elaboração do pensamento com os instrumentos conceituais e os processos de investigação da ciência que se ensina (LIBÂNEO, 2008).

Neste sentido, seguindo Libâneo (2008, p. 65), o trabalho docente precisa ser compreendido "[...] como mediação entre a cultura elaborada, convertida em saber escolar, e o aluno que, para além de um sujeito psicológico, é um sujeito portador da prática social viva". O trabalho pedagógico a ser desenvolvido é proporcionar aos alunos meios de apreensão de conceitos científicos e de desenvolvimento "[...] das capacidades cognitivas e operativas, dois elementos da aprendizagem escolar interligados e indissociáveis" (LIBÂNEO, 2008, p. 65).

Libâneo (2008) discute que as produções acadêmicas mais atuais sobre a didática utilizam a palavra "mediação" para mostrar que o trabalho do professor no ensino é o de criar possibilidades de mediar a relação entre o aluno e o objeto de conhecimento. Para o autor, trata-se de uma mediação em duplo sentido: um que leva em consideração a mediação cognitiva, na tentativa de conectar o sujeito ao objeto de conhecimento; e outro 
que trata da mediação didática, que visa dar condições e meios pelos quais o sujeito se relaciona com o conhecimento.

Com base nesta discussão, compreendemos que o processo de mediação pedagógica pode estar comprometido no período da pandemia, uma vez que depende da resolução de dificuldades técnicas de acesso e de manuseio das tecnologias digitais, bem como de aceitação do formato de ensino com distanciamento físico entre professores e alunos. Outro aspecto que dificulta a mediação do professor se refere às possibilidades de interação e comunicação com alunos, considerando-se a participação nas atividades síncronas e assíncronas. A experiência das atividades escolares não presenciais durante a pandemia pode contribuir com a aprendizagem sobre as tecnologias de ensino, porém, implica em estudos para a identificação e superação de desafios que comprometem a mediação pedagógica.

Entendemos que é necessário investir na preparação de professores e alunos para o desenvolvimento de atividades não presenciais, com abordagem sobre as concepções que fundamentam esse formato de ensino, além das questões relativas às tecnologias digitais, destacando-se, ainda, a importância de condições institucionais adequadas para o desenvolvimento da mediação do professor, com base em uma postura política comprometida com a qualidade do processo de ensino-aprendizagem.

\section{Referências}

AGUIAR, W. M. J. A pesquisa junto a professores: fundamentos teóricos e metodológicos. In: AGUIAR, W. M. J. (org.). Sentidos e significados do professor na perspectiva sócio-histórica: relatos de pesquisa. São Paulo: Casa do Psicólogo, 2006. p. $11-22$.

ARAÚJO, C. H. S.; PEIXOTO, J.; ECHALAR, A. D. L. F. O trabalho pedagógico na educação a distância: mediação como base analítica. Revelli, Inhumas-Go, v. 10, n. 3, set. 2018, p. 273-297.

BELLONI, M. L. Educação a distância. 7. ed. Campinas: Autores Associados, 2015. BRASIL. Parecer $C N E / C P n^{\circ}$ 5. Dispõe sobre a Reorganização do Calendário Escolar e da possibilidade de cômputo de atividades não presenciais para fins de cumprimento da carga horária mínima anual, em razão da Pandemia da Covid-19. Disponível em: http://portal.mec.gov.br/. Acesso em: 5 out. 2020.

COLL, C.; MONEREO, C. Educação e aprendizagem no século XX: novas ferramentas, novos cenários, novas finalidade. In: COLL, C.; MONEREO, C. Psicologia da educação 
virtual: aprender e ensinar com as tecnologias da informação e da comunicação. Trad. N. Freitas. Porto Alegre: Artmed, 2010, p. 15-46.

CONSED. Conselho Nacional de Secretários de Educação dos Estados e Distrito Federal. Monitoramento da suspensão das aulas presenciais. 2020. Disponível em: https://consed.info/prazos/. Acesso em: 16 nov. 2020.

FENEP. Federação Nacional de Escolas Particulares. Mapa de Retorno das Atividades Educacionais presenciais no Brasil. 2020. Disponível em: https://www.fenep.org.br/single-de-noticia/nid/atualizacao-diaria-mapa-de-retorno-dasatividades-educacionais-presenciais-no-brasil/. Acesso em: 16 nov. 2020.

FCC. FUNDAÇÃO CARLOS CHAGAS. Educação escolar em tempos de pandemia. Informe n. 2, 2020. Disponível em: https://www.fcc.org.br/fcc/educacao-escolar-emtempos-de-pandemia-informe-n-2. Acesso em: 10 out. 2020.

INEP. Instituto Nacional de Estudos e Pesquisas Educacionais Anísio Teixeira. Censo escolar de 2019.Disponível em: http://portal.inep.gov.br/censo-escolar. Acesso em: 8 out.2020.

KENSKI, V. M. Interações em $e$-learning no ensino superior. In: DIAS-TRINDADE, J. MOREIRA, A.; FERREIRA, A. G. Pedagogias digitais no ensino superior. Coimbra, Portugal: Cinep/IPC, 2020. p. 65-82.

LALUEZA, J. L.; CRESPO, I.; CAMPS, S. As tecnologias da informação e da comunicação e os processos de desenvolvimento e socialização. In: COLL, C.; MONEREO, C. Psicologia da educação virtual: aprender e ensinar com as tecnologias da informação e da comunicação. Trad. N. Freitas. Porto Alegre: Artmed, 2010. p. 47-65.

LEITE, S. A. S. (org.). Afetividade e práticas pedagógicas. Temas em Psicologia, Ribeirão Preto-SP, v. 20, n. 2, p. 355-368, dez. 2012.

LIBÂNEO, J. C. Didática e epistemologia: para além do embate entre a didática e as didáticas específicas. In: VEIGA, I. P. A.; D’ÁAILA, C. (org.). Profissão docente: novos sentidos, novas perspectivas. Campinas: Papirus Editora, 2008. p. 59-88.

LIBÂNEO, J. C. Didática e trabalho docente: a mediação didática do professor nas aulas. In: LIBÂNEO, J. C.; SUANNO, M. V. R.; LIMONTA, S. V. (org.). Concepções e práticas de ensino num mundo em mudança: diferentes olhares para a didática. GoiâniaGo: Ceped/Ed. da PUC Goiás, 2011, p. 85-100.

MOREIRA, J. A.; SCHLEMMER, E. Por um novo conceito e paradigma de educação digital onlife. Revista UFG, Goiânia, v. 20, n. 26, jan. 2020. Disponível em: https://www. revistas.ufg.br/. Acesso em: 11 out. 2020.

UNESCO. Organização das Nações Unidas para a Educação, Ciência e Cultura. Educação: da interrupção à recuperação. 2020. Disponível em: https://pt.unesco.org/covid19/educationresponse. Acesso em: 16 nov. 2020. 
225 Polyphonía, v. 31/2, jul.-dez. 2020

VIGOTSKI, L. S. A formação social da mente: o desenvolvimento dos processos psicológicos superiores. 6. ed. São Paulo: Martins Fontes, 2003. (Textos originais de diferentes datas).

VIGOTSKI, L.S. A construção do pensamento e da linguagem. 2. ed. Trad. P. Bezerra. São Paulo: Editora WMF Martins Fontes, 2010. (Textos originais de 1934).

Recebido em: 20 out. 2020.

Aceito em: 10 nov. 2020. 